\title{
Green Human Relations: The Concept of Sustained Development Growth along with Its Proportions
}

\author{
Mamadou Saliou Ly and Abdul Gassim Toureh
}

\section{ABSTRACT}

\begin{abstract}
Sustainable development is the improvement which encounters requirements for the actual descent wanting accommodation capacity for the prospective descent that can encounter the demand and yearning they required - which continues in various lines. We are living in an energetic world of perennially changing demands and benefits of people. Attaining economic sustainability, thereby, becomes obligation as well as challenging. The problem of sustainability has been conducted by various business organizations in different methods. Endeavoring towards three goalsenvironment protection, economic development and social wellbeing cooperatively, assures sustainability in organizations. The paper focuses on the practice of human resource policy and its features such as labor force planning, green health along security administration, and the model for sustainable organization among green human relations along with the concept of sustained development growth with its proportions. For this study, we will require secondary source among different magazines or publications, reports as well as database in- order to accomplish this work.
\end{abstract}

Submitted : December 27, 2020

Published : February **, 2021

ISSN: $2684-1827$

DOI: $10.24018 /$ ejfood.2021.3.1.213

\author{
Mamadou Saliou Ly * \\ College of Finance and Economics, \\ Gansu Agricultural University, China. \\ (e-mail: saliouly@outlook.fr) \\ Abdul Gassim Toureh \\ College of Business Management, Kofi \\ Annan University of Guinea, Guinea. \\ (e-mail: gassim20032001@yahoo.fr)
}

*Corresponding Author

Keywords: Green HRM, Green HRM practices, Green Business model, sustainable development, dimension of sustainability.

\section{INTRODUCTION}

Sustainability means to satisfy the requirements of actual phase except compromising a capacity of the prospective descent in fulfilling the needs they required. That is, our actions today will shape our future. Therefore, we require acknowledging the important of future generation as well as of current generation and move in coherence such that a balance is sustained attaining both generations' needs. The idea of development is imperfect without making room for sustainability in development.

Change in climate is an actuality, some scholars discussed that our surrounding capacity is about to be damaging and wide run inundations, clime distortions are obviousness the overall caution event. At present, it is an obligation for us to look for our grooves as well as gravely correcting them intend awareness attempt in directing surrounding problems with seniority foundation. A significant tenable improvement will be observed in the face of the fact; the UN tendered the latest direction to the entire regions in order to obey until 2030. Tenable improvement appeals to screen a scale between development and the environment. It instigates intergenerational equity, i.e., the benefit from development has to be equalized with its effect on the environment for current and future generations. While development is essential or in fact essential, the effect on the environment must be studied before undertaking such development [1]. Ecological viable is disseminated alongside prosperous commitment along with tactics that preserve our environmental advantage besides surroundings to assure defend of genuine verdure and further significance upon guarding the genuine aid substantial approach for humankind extant. The people who are included in the community along with community is unable to subsist wanting compatible surroundings. Thereupon, individuals ought to cut the gloomy effect underneath nature across efficient accountability. Moreover, it includes squander diminish or demanding even so obtain large capacity toward engagement of affair in improving processes that may aid also help the prospective line besides wealth. The ecologic feasible is a crucial challenge that needs deep abet each of the contributor to assure naught impact upon anthropogenic activity which vessel ensure the nature [2].

Liberal deterioration of the organic surroundings caused by individual human operation carried concerning a requirement in a way that can be presented with an idea of tenable improvement. Thus, organic surroundings also resort defends towards the interest for the prospective descents have been changed to entire obligations. With this stressed it is entailment to specify again the performing tactic of modern companies. The resistant outgrowth model allocates along achievement of profitable aim and the entailment that can attend widely apprehended friendly and natural benefits, putting substructures where a tenable affair paradigm founded on rules of worth also 
friendly duty directed supervising may be constructed. Resistant improvement can be an idea replying on comparative with the entire issues to human action together improved and processing counterparts. The civilization processing which comes with such a brilliant idea can be the outcome for the requirement to alleviate also warns some impacts of lucrative improvement. It is a contemporary guidance of lucrative improvement, emphasizing the presentation of the latest process of organization also supervising, together on the national stage and the grades of various lucrative realities, and the substitution of the bulkily as well with tech and natural surroundings. Some scholars agreed that, economic sustainability indemnifies the requirements of the actual descent except jeopardizing the capacity of prospective descents to indemnify theirs [3].The environmental policy region turned out to be confronted an issue even so encouraging course across organizations; besides the problem of naturalist has also in general shifted to specific transacts to battle clime alteration, from 1990s [4].The researchers identified that environmental deterioration also clime alteration have grown between increasingly insistent challenges of the actual age out coming within lucrative dooms from season also clime comparative to damages such as, dryness and warm flutter. Due to individual actions an evaluation has been made which showed about $1.75 \mathrm{C}$ of global warming above pre-industrial stages. Furthermore, hundred researchers indicated that a temperature raise 2.5 to 10 degrees over the coming age. Ascending oceans and raising offshore inundation, periodical and heavy heat weaves, widespread forest death, increasing health effect, severe droughts in some areas, changing seasons, all are the factors that influence the global climate change. They also argued that affair zone has been always at the centerpiece of all resistant examinations are deemed responsible for the natural harms both in sectional, provincial and universal run. In accordance with the laboring paradigm of affair ethics surrounding is the mainstays of corporate friendly duty (CSR) in developing a tenable affair. Attaining environmental sustainability needs reform in affair transaction and the way products and services are handed over. Human relations could be displayed as though the process for organizations to implement their CSR. Human relations are significant for the prosperous practice of human tactics along with environmental control implementations [5]. Nowadays the surroundings matter has been exhibiting intensified benefit all around the worldwide without taking into account of comparative yields be it government, collective, or phenomenon. The current benefit in naturalist in general has risen through particular transacts to fight against clime alteration. Beholden to malignant outcomes of manufacturing dirtiness and tools, including toxic chemicals, regions around the worldwide instigated rules and policies along the impact of decelerating and to some knowing even knock over the damage of natural resources and its negative impact on the humanity and the association as a whole. A number of studies conducted there are also increasing matters on the effect of climate fluctuations on cultivation. Such effect at different country levels and food security issues.

\section{Methodology}

The paper is an explanatory exploration depends on preliminary magazines or publications, and database comparable towards subject analysis as though human capital management, sustained development growth as well. Literatures will be reviewed with an orderly process. The study will attempt to obtain the subject established on information and acquaintance and keen the method to perform sustainable development across GHRM implementations from comparative liberal arts. The research will define several tenures linked upon the theme concern. Researchers discovered multiple essays comparative on the research and these will be chosen haphazardly so that we will attain the objective of the research.

\section{A. Objectives}

The broad objective of the research will be the way to examine the human relations towards economic sustainability along with how human relations ramifications work through sustainability.

\section{B. Specific Objectives}

1) To understand the position of human relations within economic growth.

2) To know the leverage of human capital strategies upon balanced growth.

3) To examine the approach of sustained development growth.

4) Rendering a methodical observation of the measurement of economic sustainability.

\section{LITERATURE REVIEW}

Substantial literatures are available on the study of economic sustainability and human resource policy. Available literatures review will be conducted to identify the development that has been made in the site.

\section{A. Human Resource Policy}

Human resource policy can be the imply of human capital management implementations, ideologies, as well as implementations upon instigate continuous operation of capital and avert hurt increasing since background effects along business organizations. Some scholars specified human resource policy as the use of Human capital Management tactics to upgrade the supportable service of assets along dealing operation together with instigates the origin of domain feasible. In the last decade, durability has become more and more unabridged entered performing line in any organization. Viable probes to scale along with comparatively optimizes ecological, collective besides commercial matters. In order organization to scale their commercial, collective besides ecological dangers, commitments along with right set of circumstances, livable 
ought to progress through being an add-on the process activities are performed [6].

To perform the structuring as well as boosting across human resource policy implementations, the structuring should pursue some verdant capacity. A number of reviewers examined different capacities through human resource policy. Contemporary scholars have discovered a portion widely accepted characteristics of human resource policy are: Human resource policy practices, labor force planning, occupational health, and security administration etc.

\section{B. Human Resource Policy Practices}

From the purpose of human resource policy practices the target is to perform human capital aware of the abode by lessen the graphite footstep of the organizations along with in instigating workers upon executing and enhancing the surroundings they live in, those who have not attended the implementations and not aware of the goals are deemed responsible for some of the difficulties various enterprises are facing. Like this profession we found that improving the nature awareness is significant, customs along with apprehending conscious the protection of the domain. Alongside human resource policy practices work forecasts in enhancing fertility reducing probabilities with defend of the benefits owned by the stockholders or investors. The significant part of human capital management within environmental control is helping the nature actions of the company as well as assorting interconnected human capital function beneath two classes comprising environmental control (EC) along with environmental management undertaking. All the ramifications are allowed by the employees, the administrations as well as aiding bureaucratic. Authors involved in green human resource management problems pull regard to several ecological implementations approach through human capital management and every scene of its method [7]. The practice of human resource policy thoughts starts since preliminary job action with plan. Various companies developed particular location in which tenant will be countable and where they will be settled in different phases along with environmental control. A significant part within effective appliance of human resource policy goes through performing and instigating workers that can help with initiating fuel-efficient actions. Literatures revealed that rural assimilation not only be a crucial element but also can aid the environmental policy that can assist to reach ecological objectives. Green Human Resource Management as a tool tactic assists organizations attain ecological objectives across developing rural ecological customs with rural workers that have been affected by nature matters, defending the environment is an important goal for organizations and the face of tabling the workers task, constantly they think organization has to compress over the abode. This conforms alongside human resource policy targets to praise ecological defense through condensing which cuts bad impacts along with boost effective impacts above the organic [8].

Like a number of scholars discovered through their investigation different workers do have conscience and comprehension on ecological system to defend the world wide along with pool the strength and protection of the nature. Those workers feel that they abetting a positive aid for the nature and the globe as well, because any time you do something that can protect the nature or the planet, once that thing shows an effective outcome definitely you will feel very touched and comfortable due to your actions and contributions. In the same way this action made the workers to feel more and more better in their mind due to the suggestion and effort they made to abet for nature and the worldwide as well. Research shows that four [4] categories engaged to appliance human resource policy practices: Gaining the nature outlook pilot, render coaching workers to work out through their ecological outlook and objectives divide ecological dispatch workers with acknowledge along with compassion workers who did good instigations in order to encourage others to do the same effort to protect the ecological actions. (Table I) [9]. The existing literature in the domain of HR on sustainable development advices that a boosting number of HR managers are willing to adjust their organization to be oriented towards environmental defend. Some researchers discovered that the combination of sustainable development, human resource management and the environment are new areas of fleet development, and thus not fully featured in the literature. They also pointed out that different HR systems must be allowed to each other in order to boost the likelihood that the organization will attain its goals [10].

TABLE I: GHRM FUNCTIONS

\begin{tabular}{ll}
\hline \multicolumn{1}{c}{$\begin{array}{c}\text { Human capital management } \\
\text { ramifications }\end{array}$} & \multicolumn{1}{c}{ Occupation } \\
\hline $\begin{array}{l}\text { Engagement of allowed labor } \\
\text { force }\end{array}$ & Job specification \\
& Engagement \\
& Commence the assignments \\
& Displacement \\
& Coaching \\
Personal administration & Health along with immunity around \\
& the workplace \\
& Self-sustaining \\
& Labor relations \\
& Instigating along with remunerating \\
& Resolution of conflicts with \\
Aid of directorial agitations & regulation \\
& Observing socialization also points of \\
& view \\
& Improving moral values \\
& Enhancing services \\
\hline \hline
\end{tabular}

\section{Labor Force Planning}

Various organizations or enterprises determine on enrolling or claim of unemployment of people that are energy-sufficient interest. Organizations are increasingly appealed for performing a group of energy-saving workers in order to appliance collective environmental policy program. This can be feasible or workable which protect along with accomplish as a process or 
method that can be involved more and more workers within the company which gains the rural interest intellectually [11].

\section{Occupational Health and Security Administration in Connection with Laborers}

Every company's fulfillment abundance together with benefit belongs upon worker's attempt the purpose together with the target of the company. As we observed through the organization, health and security are two main paramount elements that any company or organization should consider at first to ensure the life of the workers and the organization as well. Coaching and improvement are implementations that concentrate on the enhancement of laborer's expertise, comprehension as well as point of views, defend the degradation, which is connected through grasp, expertise also vantage of point. Green coaching and improvement can train peasant and support them in many ways or methods which can preserve power, cut squander, broadcast nature consciousness along with chance which can involve stiff within ecological disorganized [12].

\section{RESULTS AND DISCUSSION}

\section{A. Nominate Paradigm of Defendable Company across HRM and Sustainable Business}

Any company or enterprise to attain it visions along with targets and running matters, it should comprehend that nominate paradigm of defendable company and sustainable business is significant. Corporation that needs to achieve the aim that has been established it is very crucial to perform it efficiently and effectively to minimize the concerns. Various contemporary scholars have indicated the different ramifications of HRM implementations to transact the organization pursuance and more efficient. In the field of business, many organizations perform trading alongside many goods. Through manufacturing upon use the company requires different scenes which can generate expendable products. Whereas in the way of generating the products, the organization gathered various wastes and refuses which are very malignant for human beings and the environment. They can be deemed responsible for many challenges that have negative impacts to the life of individual human and the environment as well. All organizations around the globe should give hands together to alert the use of plastic, energy loss and anything that can cause the pollution through the air as well as in the sea inorder to forecast the hurt of the nature and human beings as well. The sustainable business to be well performed, the affair should drive alongside essential assets, bountiful goods, minimizing the plastic use, energy wastage, reduce the usage of organic matter ,changing the way of wraping,dispersal as well as advertising etc. when the company implement positively and efficiently the elements that are illustrated above, not only it can support us to reduce the probabilities that human beings afraid of but also can aid to minimize the global warming that is malignant for our ecological system or environment. Global warming is the general challenge for all the nations of the world. Every region ought to have regard for the environment as a whole; we can have safety and health if our surroundings is secured from any danger that can be occurred. So, it is substantial for us to stay away from anything that can hurt the abode so that we can have an abundance security. Sustainable business should pursue green human practices. The first stage's factors are composed of different contents that aid to express sustainable business while on the other hand, the second section's zone contain the human resource policy. These two factors none can work in the absence of the other they must be combined and technically implement both of them together efficiently and effectively to attain the goal or objective of the organization or enterprise.

TABLE II: PARADIGM OF BALANCED GROWTH ACROSS SUSTAINABLE BUSINESS ALONG WITH HUMAN RESOURCE POLICY

\begin{tabular}{|c|c|}
\hline & Components \\
\hline$n$ & Assets or goods \\
\hline$\stackrel{\infty}{=}$ & Sustainable goods \\
\hline$\overline{\underline{5}}$ & Eco-friendly \\
\hline 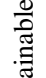 & $\begin{array}{l}\text { Minimizing the usage of } \\
\text { ductile }\end{array}$ \\
\hline$\stackrel{\vec{\vartheta}}{\vec{n}}$ & Cutting energy loss \\
\hline
\end{tabular}

Human resource policy Components

\begin{tabular}{|c|c|}
\hline & Green model \\
\hline & Labor force planning \\
\hline & Green engagement along \\
\hline & with collection \\
\hline & Green coaching with \\
\hline & Green entertainment along \\
\hline & bunting administration \\
\hline & $\begin{array}{l}\text { Green health along with } \\
\text { security administration }\end{array}$ \\
\hline
\end{tabular}

Fuel-saving
Ecological label
Reducing the use of
basic material
Green covering
Green dispersal along
with advertising
Green client support
team an along
Disposal of waste
Green analysis als al
with reinforcement

Source: developed by the authors.

\section{B. Strain Connected Besides the Explanation of the Long-term Growth}

The idea of long-term growth is essential for us to pull regard to comprehend that various denotations belonging to the construe scholars with the idea that can be utilized. Different dimensions of economic sustainability have been conducted that can be enclosed numerous for the idea of long-term growth to attain the purpose of the paper. Issues combined from the answer of tenable illustrate that the lasting development indicate along with has many dimension issues which contrive effectiveness, decency also generational decency established above sides. As though general idea, lasting development surrounds threesome essential perspectives which are listed below: wealth, ecological, along with community progress that is supplementary connected [13].

Customarily, the long-term growth concept implies into threesome identical constituents: ecological, wealth, along with 
community progress; with trey aspects of welfare for instance profit-making, environmental as well as collective, besides intricate interconnection they gain that probed within the paper with further explanation. Many interpretations on the term of long-term growth tendered from country appears around 1980s as though likable pilot standard toward the global collective. Upon emphasize on intrinsic cultural diversity, scholars look forward to improving and probe the economic sustainability as well as supporting capacities of welfare. The fundamental concept that is after the approach of long-term growth was nearly about a decade. As the UN retrieve mutual prospective in 1987, well-known as though researchers specified the longterm growth like improvement that encounters the requirements for the actual descent absent wanting capacity for the prospective descents that can encounter the demand and yearning, they required. For about two decennary downstream this quote interpretation nevertheless remains universal. As we observed, scholars, researchers and literatures both of them agreed that this is the most universal elucidation with these though numerous scholars always refer to this standard explanation to expand their thoughts [14]. Economic sustainability flashes part of the directing goals of humanity over the present-day contrary the belief of the syndicalism previously. Undoubtedly, improving balanced growth use will improve the environmental footprint and thereby abet to the global of economic sustainability. Many contemporary scholars support the definition given by the UN report about sustainable development their idea is that the approach was established over threesome main strays named final decision or essence. Earliest prop conceals ecological improvement, the next pier screens profit-making, and the threefold pier conceals social advancement. Such a thing hardened in the middle of 1960s as though an answer to a speedy boosting populace along with comparative probabilities like exaggerating the usage of raw materials, ecological contamination, dismissed rate malnourishment as well as deterioration of the planetary surface distinctively of the woodland. The UN and other institutions should pay more attention about this matter because it is a global issue not individual one. They should come together to discuss and find suitable solutions to tackle these challenges which are common globally failure to do so, we are very afraid that it will be very difficult for us to live descent life conveniently as we wish. We hear about health and safety if the environment is safe otherwise it is impossible.

\section{Argument through Economic Sustainability among Various Educational Points of View}

In turns out that, various themes economic sustainability is elucidated otherwise within business is the improvement assuring the income per inhabitant of prospective descents less than the existing descents. Within social -science economic sustainability can be an improvement which conserves the populace. For instance, sustain beneath social integration within the societies. Within environment the economic sustainability can be the process or method that conserves variety of organic breed, significant biosphere along with environmentally safe methods. Issues connected with tenable describe the economic sustainability is compound besides many-dimensional problems that must contrive effectively, rights above profit-making, community, along abode basis. Argument concerning lasting development existing within the scholars is possible to be categorized through various particular zones: Theorical, Educational, along Intergovernmental [15]. At the moment that scholars along investigators attribute the circumstance of the economic sustainability the governmental along with the educational approaches' phases are evaded.

Governmental posture ascribes through accordance along with tactics implied within the approach of economic sustainability that was attained along the worldwide harmony. Organization conceivably apprehended as though process that is eligible to be utilized meanwhile determining who will perform the commitments in particular bazaars and what kind of achievement can be attainable along with what exploits will be bounded. Talking about the situation of the institution these elements should be considered and deeply apprehended in order to attain positively and efficiently the goal. The educational situation is connected through scientific methodology that recently established through governmental discussions like the indigenous root of disclosure of the idea

\section{The Proportions of Economic Sustainability}

As though common idea, lasting development retains threesome essential outlets: benefit-making, ecological along with community developments that are linked mutually. Customarily, economic sustainable approach implies threesome identical parties: ecological wealth along with community with the compound interconnected they have. Economic sustainability can be a definite accommodation amid ecological, wealth, with the community targets of the society enabling welfare for the prospective descents that are existing. Existing the idea of the long-term growth as though dimensional, for instance trey enclosing threesome zones: wealth, ecological and collective. For the objective of the further investigation will be helpful in assimilating trey representations through lasting development (wealth, abode, also community) discovered across current compositions synchronical, and that is very entailment for us along with practice in a way that can discern economic sustainability is far to be uncomplicated bond. As though suggested, the economic sustainability tools must be identically allocated in order the expected outcome may be attained efficiently and effectively.

\section{E. Economic Proportion of Balanced Growth}

Magnified theory on capital that may gain through economizing fundamental fixed assets to make benefit for the prospective descents, practicing the fundamental of equitable dispersal of the descents. Sustainable economic growth pursues the way to enlarge as much as possible the cast of resources along with duplication which may be produce meanwhile 
always sustaining a load resources that produce advantageous productions. A number of literatures have revealed that feasible starting generally requires enough savings in order to defeat lasting wanting financial wellbeing that they ought to be considered such a business problem of lasting development. The main goal of the practice through durability precepts can be harboring the highest sum of ways and means for future generations. As lasting development is deep-rooted forecast too, an enterprise will be regarded as feasible when it performs footsteps that can reassure to enhance the enterprise concurrences [16].

\section{F. Ecological Proportion of Economic Sustainability}

The environmentally safe concept through economic sustainability pulls regard at feasible along corporal framework also ascribes through scientific works. In agreement with the concept, the fundamental assignment with economic growth that can be decided on the way to limit the ecosystem for many commercial occupations. In view of this circumstance, the energy of scheme flatters significantly within crucial perspective worldwide perseverance of the ecological community. Therefore, a fundamental protection of botanical diversity can be intoned to ensure scaled essence, the flexibility of environment upon worldwide stage with the capability they have in adjusting with alterations within the environment along with their capacity in ensuring prospective alternatives. Some scholars agreed that the environmentalfriendly attack may be settled besides gaining knowledge. In order to improve assessment, facts have to be touched alongside paradigm bazaars beside operator. Environmental control is the device of information retrieval of problem solving comprehension among the areas of administration along environmental monitoring as well as information technology. The use of computing resources will support to develop more feasible world [17].

\section{G. Societal Proportion of Economic Sustainability}

Balanced growth is about equity along with the current generation and between the present and the prospective generations. The civil society feasible approach flashes the articulation in the middle of improvement along with overpowering collective average along strains also sustains the solidity of gregarious structure. Collective feasible looks for diminishing defenselessness and sustains the fitness of communal along with customs scheme as well as their capacity to resist concussion. Civil society feasible needs leastways protection for another crucial ingredient of social bond, and the hindmost is apprehended as though capability of the community toward figuring out collective, wealth, ecological issue besides being potent within creating enhancement for the entire organization. Liability for the worldwide demands universal agreement besides reinforcement, established above a methodical toward actuality, comprehensive, perceives the ecosystem along mankind as though a single structure, also a universal lifestyle foundation. Economic growth currently depicts previously mentioned collective responsibility. In economics, believes that companies should fulfill to focusing as much as social and environmental or ecological concerns as they do on profit by [18].

\section{CONCLUSION}

From on top explanation, we can observe various justifications to pass but there is no another alternative that is suitable to be used to secure corporate sustainability wanting one and the other hand sustainable business along with human capital management which are human resource management, human resource policy, labor force planning, green safety along with relations with laborers as well as sustainable business simultaneously able to transact a company or enterprise durability. The examination of sustained development growth approach elucidation substantiates also within all the centenary definitions of sustained development growth none of them is discovered within scholars enclose the entire angles of the approach along with render complete apprehending the concept.Thus, this can be stretched toward reckon the great suit elucidation which sneezes out of sustained development growth approach is furnished towards scholars certifying that sustained development growth ascribes the improvement which indemnifies the requirements of the current year wanting compromising the capacity of prospective descents to indemnify their requirements. Issues connected towards sustainable development demonstrate balanced growth is compound along with various dimensions' problem that should contrive effectively and efficiently rights besides generational rights above wealth, community, environment or ecological.

\section{RECOMMENDATIONS}

Sustainable business is very payable along comprehensive oncoming both personal and current alignment all around the globe. The universal seriously requires sustainable business ramifications towards avert also defend through harms. Gleaned from explanation, as it may be signed that sustainable business along human resource policy might supplement ecological dispatch in a body that could help the company or enterprise to have more feasibility along with the globe. The connections absorbed towards balanced interpretation do not possess notwithstanding pertinence along with the identical definition towards tactics tools through geographical balanced growth. Connections in the middle of scheme absorbed have a duty to be shifted towards rational framework established at length the purpose of the perceptive instrument to be constructed. Achieving such kind of stratified structure alongside logical feasibility rational would be required. 


\section{ACKNOWLEDGEMENT}

We would like to express our gratitude towards previous researchers and method managers, who have examined upon the problems of sustainable business, Human relations practices and feasibility. Without their support, we could not have written this paper.

\section{REFERENCES}

[1] Al Mamun, M. A. (2019). An Analysis of Employee Awareness on Green Human Resource Management Practices: Evidence from Bangladesh. Human Resource Management Research 2019, 9(1): 1421,8 .

[2] Aykan, E. (2017). Gaining a Competitive Advantage through Green Human Resource Management. Erciyes University, Kayseri, Turkey, 19.

[3] Benjamin. (2018). Green Human Resource Management: Policies and Practices for Sustainable. The Kerala State Cashew Development Corporation Ltd, 8.

[4] Bombiak Edyta, I. a.-K. (25 May 2018). Green Human Resource Management as a Tool for theSustainable Development of Enterprises: Polish Young Company Experience. Faculty of Economic and Legal Sciences, Siedlce University of Natural Sciences and Humanities, Konarskiego 2,08-110 Siedlce, Poland; anna.marciniukkluska@uph.edu.pl, 22.

[5] Bombiak, E. I.-K. (25 May 2018). Green Human Resource Management as a Tool for theSustainable Development of Enterprises: PolishYoung Company Experience. Faculty of Economic and Legal Sciences, Siedlce University of Natural Sciences and Humanities, Konarskiego 2,08-110 Siedlce, Poland; anna.marciniukkluska@uph.edu.pl, 22.

[6] Ciegis, R. J., \& Martinkus, B. (2009). The Concept of Sustainable Development and its Use for Sustainability Scenarios. 1Vilnius University, Kaunas Faculty of Humanities, 10.

[7] Ciegis, R. R., \& Bronislo, J. (2009). The Concept of Sustainable Development and its Use for Sustainability Scenarios. Vilnius University, Kaunas Faculty of Humanities, 10.

[8] Drela, K. (25.03.2020). Sustainable management of human resources in enterprisesas an example of sustainable development. Scientific Journals of the Maritime University of Szczecin, 8.

[9] Kathak Mehta, P. K. (2015). Green HRM in Pursuit of Environmentally Sustainable Business. Universal Journal of Industrial and Business Management 3(3): 74-81, 2015, 8.

[10] KENTON, W. (JULY 2020). The Triple Bottom Line. Corporate Finance and Accounting, 7.

[11] Muthu, M. K., \& Arunadevi, S. (2019). Green and Sustainability in Software Development Lifecycle Process. Department of Science and Humanities, Kumaraguru College of Technology, Coimbatore, India, 17.

[12] Muzahidul Islam, M. (2019). Green HRM and Green Business: A proposed Model for Organisational Sustainability. Department of Management studies,Patuakhali Science and Technology University, 2019.

[13] Piwowar-Sulej, K. (January 2020). Human resources development as an element of sustainable HRM-with the focus on production engineers. Journal of Cleaner Production, 15.

[14] Sachdeva, D. G. (2018). Human Resource Management for Sustainable Development. Jagannath International Management School, 22.

[15] Shafaei, A., \& N. (2020). Green human resource management: A twostudy investigation of antecedents and outcomes. International Journal of Manpower, Advanced online publication. https://doi.org/, 22.

[16] Shafaei, A. M. (31 August 2019). Green humanresource managementA two-study investigation of antecedents andoutcomes. School of Business Management, Universiti Utara Malaysia,Sintok, Malaysia , 21.

[17] Sharma, K. F., \& Vashistha, U. (2019). Green HRM: An Employee Interface for Sustainable Development. Seventeenth AIMS International Conference on Management, 8.
[18] Shen, J. F., \& Siddiq, K. H. (2018). Sustainable Resource Use in Enhancing Agricultural Development in China. National Academy of Agriculture Green Development, Center for Resources, Environment and Food Security, College of Resources and Environmental Sciences,China Agricultural University, Beijing 100193, China, 2.

[19] Steurerr, R. M., \& Konrad, A. (29-02-2016). Corporations, Stakeholders and Sustainable Development I: A Theoretical Exploration of BusinessSociety Relations. ournal of Business Ethics, Vol. 61, No. 3 (Oct., 2005), pp. 263-281, 20.

[20] Vries, B. J., \& Petersen, A. C. ( $\left.\begin{array}{llll}2 & 0 & 0 & 9\end{array}\right)$. Conceptualizing sustainable developmentAn assessment methodology connecting values, knowledge,worldviews and scenarios . Netherlands Environmental Assessment Agency, P.O. Box 303, 3720 AH Bilthoven, The Netherlands, 14.

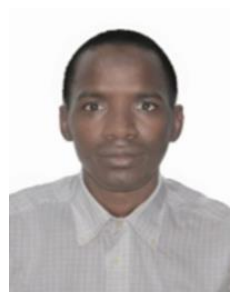

Mamadou Saliou Ly is a Guinean by nationality. He holds a Diploma of Social Sciences and a Bachelor of Business Administration from Kofi Annan University of Guinea respectively. Since 2016 to 2018 he was teaching English from private and public schools in Guinea. He has found that in order to expand his knowledge he should integrate in education because in education he can learn every day and perform increasingly .In 2019, he came to china with the aim of pursuing his studies in the field of Agricultural Management .Actually; he is an Agricultural Management Student at Gansu Agricultural University in Gansu province. He will further his education whether in European countries, America or Australia. He thinks that education is the main key for the mankind to live in this globe without any anger, stress, and anxiety, hopeless. He thinks that education can support the humanity to attain significant objectives, visions, and goals as well. After finishing his professional career, he would like to go back home to give service of the knowledge that he gained to his people in order to support the development of the country and instigate youth to do as he did which can lead long-term achievement of the nation.

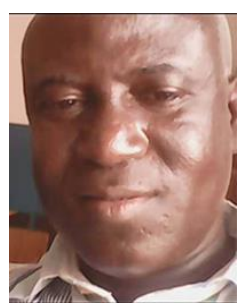

Mr. Abdul Gassim Toureh was born in Guinea Conakry in 1970. He graduated from a prestigious University in Serra Leon with Higher National bachelor's degree in Business Accounting. He holds PHD degree in the field of Business Administration. He is fun, active, encouraging and supportive teacher to all his students. Teaching is his passion. He is always available to support those who are in need. He is a famous teacher in the country. He is brave, brilliant, and excellent teacher. $\mathrm{He}$ instigates and coaches many youths in personal development that gives an effective result to the youth to create their own enterprises and businesses. Presently, he is promoted by the government in the field of economics and finance due to his devotion to support youth. He has always many methods to prove to the youth that everything they want to have are in the country with a concrete prove that impressed a lot the youth. 